\title{
Contact-2: a computer-assisted instructional strategy for promoting conceptual change
}

\author{
HARM J. A. BIEMANS ${ }^{1}$ \& P. ROBERT-JAN SIMONS ${ }^{2}$ \\ ${ }^{1}$ Department of Agricultural Education, University of Wageningen, P.O. Box 8130,6700 EW \\ Wageningen, The Netherlands; \\ ${ }^{2}$ Department of Educational Sciences, University of Nijmegen, P.O. Box 9104, 6500 HE \\ Nijmegen, The Netherlands
}

\section{Received 27 June 1994; accepted 22 November 1995}

\begin{abstract}
Previous research seems to support the assumption that students need instructional guidance to activate and correct their preconceptions. Such an instructional strategy is the CONTACT strategy, characterised by continuous, computer-assisted activation of the conceptions of individual leamers. Our previous study showed that the CONTACT strategy was effective in promoting conceptual change in text processing (domain: physical geography) because students (fifth- and sixth-graders, primary education) constructed more conrect conceptions. However, students mainly seemed to focus on the central concepts from the training texts, disregarding other information. Therefore, the strategy was adapted to solve this problem of selective attention and to increase its effectiveness. Subjects ( $74 \mathrm{fifth}$-and sixth-graders) were assigned to three instructional conditions (original CONTACT condition, revised CONTACT-2 condition and control condition NO ACTIVATION). A mixed between-within-subjects design was used with 2 between-subjects factors (instructional condition and students' familiarity with the central concepts from the 7 texts used). Dependent variables concerned quality of conceptions and learning performance. Students from the CONTACT- 2 condition constructed better conceptions and achieved higher leaming performance scores than students from the other two conditions. Moreover, the effectiveness of the CONTACT- 2 strategy appeared not to depend on the degree of conceptual resemblance between the performance test questions and the central concepts from the texts and on the moment of testing. Additional research should shed some light on the instructional conditions required to teach students how they themselves can initiate and perform leaming activities aimed at conceptual change.
\end{abstract}

\section{Introduction}

One of the main principles of recent constructivist learning theories states that learners should be considered as active constructors of knowledge: "at any given point, the learner has a store of knowledge about scientific topics that are his/her constructions of reality based upon his/her experiences or interactions with the real world" (Hegland and Andre, 1992: 233). This knowledge serves as the starting point for future learning (Voss, 1987). Prior knowledge can enable the learner to relate concepts, to think of examples, to structure the learning material, etc. (Vermunt, 1992). In this way, prior knowl- 
edge activation can support knowledge construction processes with deeper understanding as a result. Prior knowledge can be described as all knowledge learners have when entering a learning environment that is potentially relevant for acquiring new knowledge (see also Dochy, 1988).

Many studies, however, have shown that not all learners hold correct preconceptions (i.e. in accordance with generally accepted scientific views): many students appear to have incomplete or incorrect ideas (see Pfundt and Duit, 1991). A similar pattern with respect to the quality of preconceptions has been found in our own experiments (see also Biemans, 1994). At this point, it should be noted that generally accepted scientific views especially exist in well-structured knowledge domains, for example the domain of basic physical geography, which has been treated in our studies. In our view, the distinction between misconceptions and correct conceptions is far less clear when advanced knowledge acquisition in ill-structured domains is concerned (see also Spiro, Feltovich, Jacobson and Coulson, 1991).

Misconceptions and incomplete conceptions can block knowledge construction processes, if they are not diagnosed and corrected during learning (see Eylon and Linn, 1988; Dochy, 1992). Even if their preconceptions are correct, few students use their prior knowledge spontaneously and actively (Ali, 1990). Apparently, for many students, strategic support needs to be implemented in the learning environment to support prior knowledge activation and knowledge construction. In this paper, the question is addressed how preconceptions can be activated and how incomplete and incorrect conceptions can be changed, in other words, how conceptual change can be achieved.

Inspired by current conceptual change approaches (e.g. Nussbaum and Novick, 1982; Hewson and Hewson, 1984; Strike and Posner, 1985; Prawat, 1989), Ali (1990) designed the CONTACT strategy. The CONTACT strategy is typified by continuous, computer-assisted activation of the conceptions of individual learners in text processing. Computer-assisted instructional strategies can enable individual students to use their own conceptions as starting point for knowledge (re)construction processes, which can hardly be realized in concrete classroom situations. Moreover, these strategies can activate them to perform learning activities aimed at conceptual change.

The CONTACT strategy is based on an instructional model consisting of five steps (see for more details Ali, 1990; Biemans, 1994; Biemans and Simons, 1995): 1) searching for own preconceptions; 2) comparing and contrasting these preconceptions with the new information; 3) formulating new conceptions, based on the previous step; 4) applying the new conceptions; 5) evaluating the new conceptions, based on the previous step. This sequence of instructional steps is always performed twice. The CONTACT strategy can 
be characterised as "process-oriented": its aim is to ensure that students perform appropriate learning activities in order to construct, change and use their conceptions of the learning content (see Vermunt, 1992).

The CONTACT strategy appeared to be more effective in fostering conceptual change than an instructional strategy characterized by activation both before and after the presentation of the new textual information (domain: physical geography; subjects: sixth-graders, primary education) (see Ali, 1990). In a previous study, this before-after strategy had been proved to be more effective than no activation or activation at either the beginning or the end of each training session (see also Ali, 1990). Nevertheless, Ali's study left several questions unanswered.

In our first study, the effects of the various CONTACT steps were examined by dismantling the strategy (see for more details Biemans, 1994; Biemans and Simons, 1993; 1995). Results indicated that the complete CONTACT strategy was more effective in promoting conceptual change than the three dismantled versions (especially for "highly familiar" fifth- and sixth-graders): students who had been assigned to the complete CONTACT condition constructed conceptions that represented the relations between the central physical geography concepts from the texts more accurately. Moreover, they achieved better learning results than the no activation control group on retention test questions that were directly related to these central concepts ("near transfer", see Simons and Verschaffel, 1992) (the retention test was given two weeks after the last training session). Nevertheless, one must also conclude that the strategy had a negative side effect: students mainly seemed to focus on the central concepts from the texts, while disregarding information that was less directly related to these concepts. This resulted in lower learning performance scores on less directly related retention test questions compared with the no activation control group ("far transfer", see Simons and Verschaffel, 1992). These findings were in accordance with the selective-attention hypothesis (see also Machiels-Bongaerts, 1993). Overall, the various instructional conditions did not differ with respect to learning performance scores. In this respect, it proved impossible to dismantle the training effects that had been found by Ali (1990), since the effects themselves were not replicated. A remarkable outcome of this study was the lack of retention loss for the CONTACT group. All other groups performed much lower at retention time than at posttest time, but the CONTACT group remained on the same level. This finding combined with the results concerning students' conceptions, gave some hope that the underlying activation model might be effective after all.

How can one explain that the CONTACT strategy was superior to the beforeafter strategy (that had been superior to a no activation control group in a previous study) (see Ali, 1990) while comparable training effects on learning 
performance could not be traced in our study? One explanation might be that the involvement of fifth-graders in our study is responsible. Perhaps the strategy is too difficult for younger students. Post-hoc analyses, however, did not reveal any differences between fifth- and sixth-graders. Another explanation might be that shortening the training from 9 to 7 training sessions is responsible for the differences between the studies. In Ali's study, there were indeed more differences at the end of the training than in the beginning (see Ali, 1990). Students need to learn how to work with their prior knowledge and how to use the help being offered. Thirdly, an explanation might be found in the students' competence level. There are indications that the students in Ali's study were of a higher competence level than the subjects in our experiment. Finally, the results might be caused by interference effects: students had to study conceptual information and had to learn how to learn at the same time. Informal observations showed that some students in our study had problems in maintaining their concentration while working with the CONTACT strategy. To conclude, instead of denying the effectiveness of the CONTACT strategy, it seems better to try to improve it.

Therefore, in the present study, an attempt was made to improve the CONTACT strategy in several ways and to prevent the selective attention phenomenon mentioned above from showing up (see also Machiels-Bongaerts, 1993). The strategy should become more flexible and offer still more help to the less competent students. Therefore, in this study, a revised variant of the CONTACT strategy, the CONTACT-2 strategy, was constructed. To be able to examine the effects of this revision, both strategies were identical with respect to the physical geography texts and illustrations being used as well as the underlying activation model.

The aim of the present study was to explore whether the adaptations of the CONTACT strategy would result in increased effectiveness in terms of conceptions and learning performance. Therefore, subjects were assigned to three instructional conditions:

1. original CONTACT condition (see for more details Ali, 1990; Biemans, 1994; Biemans and Simons, 1993; 1995);

2. CONTACT-2 condition (see section "Instructional conditions");

3. NO ACTIVATION condition (see for more details Biemans, 1994; Biemans and Simons, 1993; 1995).

We hypothesized that the CONTACT-2 strategy would be the most effective variant. Whereas the CONTACT-2 strategy was supposed to be more flexible than the original CONTACT strategy, we assumed that it would be more effective both for students who were very familiar with the central concepts from the texts being used and for students who were not very familiar with these 
concepts before the training. According to our expectations, the CONTACT- 2 strategy would serve the needs of both groups of students.

Moreover, the CONTACT- 2 strategy was characterised by various adaptations to solve the problem of selective attention. Therefore, we hypothesized that the CONTACT-2 strategy would lead to higher learning performance scores both on questions that were directly related to the central concepts from the texts and on less directly related questions. Finally, we assumed that the revised variant would result in the best maintenance of the acquired knowledge.

\section{Method}

\subsection{Subjects}

Subjects were 74 students, ages ranging from 10 to 13 . They were attending three different classes of the same two primary schools that had participated in our previous study (29 fifth-graders and 45 sixth-graders). After being matched based on their competence level (reading comprehension as judged by their teacher) and their grade, subjects were assigned to the three instructional conditions at random.

\subsection{Instructional conditions}

Subjects were assigned to three instructional conditions: the original CONTACT condition $(\mathrm{N}=25)$, the CONTACT- 2 condition $(\mathrm{N}=25)$ and the NO ACTIVATION condition $(\mathrm{N}=24)$. The CONTACT condition and the NO ACTIVATION condition were identical to the conditions of the same name used in the previous study (see for more details Ali, 1990; Biemans, 1994; Biemans and Simons, 1993; 1995). The revised variant of the CONTACT strategy, the CONTACT-2 strategy, was based on the conclusions from our previous study.

To increase the efficiency and flexibility of the strategy, various adaptations aimed at supporting conceptual change processes were made:

1. In the steps of the original CONTACT strategy, additional strategic information in the form of "How" and "Why" parts is included (see also Biemans, 1989; Biemans and Simons, 1992): the "How" parts contain information about how that particular step can be realized and in the "Why" parts the relevance of the particular step is explained. When the student is executing a particular step of the CONTACT-2 strategy, however, the corresponding "How" and "Why" parts are optional. During the first sequence of steps, the monitoring question "Do you understand what to do with this step?" is always posed before the student can execute a particular step. In case of a negative answer, the student has to study the corresponding "How" parts 
before executing the step. In case of an affirmative answer, the student can execute the step immediately. During the second sequence of steps, the "How" and "Why" parts are fully optional: monitoring questions are omitted.

2. If the student has a correct conception at the end of the first sequence of steps, the second sequence is not presented: the CONTACT- 2 strategy is more sensitive to the student's progress.

3. All learning activities corresponding to a particular step of the CONTACT-2 strategy have to be done on one "execution screen" of which all elements are labelled in different colours: the "execution screens" of the various steps are made more surveyable.

4. After each "execution screen", the student is asked if he/she has written down the requested information on the work sheet to ensure that he/she executes the particular step in a profound way.

5. With the steps "searching for own preconceptions", "formulating new conceptions" and "applying the new conceptions", the student can ask for a corresponding picture: both textual and visual presentation modes are used to optimize the student's opportunities to activate his/her conception ("multiple bridging"; see also Spiro, Feltovich, Jacobson and Coulson, 1991).

6. With the steps "comparing and contrasting the preconceptions with the new information" and "evaluating the new conceptions", crucial concepts are accentuated in different colours to focus the student's attention on the essential elements from his/her conception and from the text.

To solve the problem of selective attention, the strategy was adapted in several respects. These adaptations were aimed at spreading the student's attention:

1. At the beginning of each training session, the goal of the training (comprehension of the whole text) is stressed.

2. Crucial concepts and relations between concepts are accentuated in red to focus the student's attention on all important information from the text.

3. The student is given the opportunity to search for information on other text screens: scrolling options are optimized.

4. The amount of strategic information the student is obliged to read, is reduced so the student can pay more attention to the text itself.

5. If the student has a correct conception at the end of the first sequence of steps, the second sequence is not presented so the student can pay more attention to the text itself.

\subsection{Design and materials}

As in our previous study, two between-subjects factors, Instruction and Familiarity, were used. The factor Instruction had three levels: the CONTACT condi- 
Table 1. N of Ss per cell for the six Instruction X Familiarity groups.

\begin{tabular}{lll}
\hline & Low familiarity & High familiarity \\
\hline Contact & 10 & 15 \\
Contact-2 & 13 & 12 \\
No activation & 12 & 12 \\
\hline
\end{tabular}

tion, the CONTACT- 2 condition and the NO ACTIVATION condition (see section "Instructional conditions") (see Table 1).

The factor Familiarity was based on students' scores on the Familiarity rating scale (see also Ali, 1990; Biemans and Simons, 1993; 1995). This rating scale was a list of 14 central concepts from the 7 training texts. With each concept, subjects had to state how often they had heard, read or seen something about that particular concept before. Based on their familiarity score, subjects were assigned to the Low familiarity group $(\mathrm{N}=35)$ or the High familiarity group $(\mathrm{N}=39)$, with the median as the criterion (see also Table 1).

The effects of the between-subjects factors Instruction and Familiarity on students' conceptions were measured by means of idea questions. An idea question could be described as a concrete problem that had to be solved by relating the central concepts from the corresponding training text. One of the idea questions ran as follows:

Suppose it's a hot, sunshiny day and you're on the beach. When you hold your hand close to the sand, you can feel the heat on your skin. What do you experience when you hold your hand higher above the sand?

Each student had to choose from six answer alternatives that corresponded to different ideas about the relations between the concepts involved in the problem:

1. Higher above the sand it's warmer because it's closer to the sun.

2. Higher above the sand it's warmer because hot air goes up.

3. Higher above the sand it's warmer because the clouds block the sunbeams.

4. Higher above the sand it's colder because sand is always hot.

5. Higher above the sand it's colder because the air gets heated from below.

6. Higher above the sand it is as warm as it is close to the sand because the sun is everywhere. 
Table 2. Within-subjects factors and their levels in the present study - mean scores were calculated by dividing the sum scores by the number of questions (see for more details Biemans, 1994; Biemans and Simons, 1993; 1995).

\begin{tabular}{lll}
\hline & Within-subjects factor(s) & Levels \\
\hline $\begin{array}{l}\text { Conceptions } \\
\text { during training }\end{array}$ & Training Time & $\begin{array}{l}\text { Preconception } \\
\text { Conception after step 1 } \\
\text { Conception after step 3 } \\
\end{array}$ \\
& & $\begin{array}{l}\text { Conception after } 1^{\text {st }} \text { sequence } \\
\text { Final conception }\end{array}$ \\
\hline $\begin{array}{l}\text { Conceptions } \\
\text { after training }+\end{array}$ & Testing Time & Immediately after training \\
ability to apply & & After two weeks \\
\hline Leaming & Relatedness & After two months \\
performance & & Directly related \\
& Testing Time & Less directly related \\
& & Posttest \\
& & Retention test 1 \\
& Retention test 2 \\
\hline Leaming & SLS-scale & Part I \\
activities & & Part II \\
\hline
\end{tabular}

The answer alternatives were based on various conceptions determined as frequently held by students in the domain of physical geography (see Ali, 1990). One of the answer alternatives corresponded to the scientific notion as explained in the text. Except for subjects assigned to the condition NO ACTIVATION, students had to state their conception at various moments during each training session $(\mathrm{N}=50)$ (see Table 2).

The quality of students' conceptions as well as their ability to apply these conceptions were also measured after the training. Immediately after each of the seven training sessions, all subjects answered the particular idea question. Moreover, they answered two practice questions treating the same concepts and relations between concepts. The same questions were posed both two weeks and two months after the last training session (see Table 2).

As in the previous study, the effects of the between-subjects factors on learning performance were measured by means of a posttest administered immediately after the corresponding training session and a retention test delivered two weeks after the last training session. In this study, however, a second - identical - retention test was administered two months after the last training session to trace the long-term training effects. All questions were classified as "directly related to the particular idea question" or as "less 


\begin{tabular}{ll}
\hline Session 1 & Familiarity rating scale \\
Session 2 & Introduction session \\
Session 3-9 & Training sessions + posttest + idea and practice questions \\
Session 10 & Statement list "Studying a text" \\
Session 11 & Retention test 1+ idea and practice questions \\
Session 12 & Retention test 2 + idea and practice questions \\
\hline
\end{tabular}

Figure 1. Procedure of the present study.

directly related" (see Table 2; for more details Biemans, 1994; Biemans and Simons, 1993; 1995).

After the training, subjects filled in the Statement List "Studying a text" (SLS). With the first part of the SLS, subjects had to identify learning activities that could be performed to construct a correct conception while studying a text. With the second part of the inventory, subjects had to state how often they had performed these learning activities during the training (see Table 2; for more details Biemans and Simons, 1993; 1995).

\subsection{Procedure}

The procedure of this experiment was comparable to the procedure of the previous study (see Figure 1; for more details Biemans, 1994; Biemans and Simons, 1993; 1995).

The seven training texts were all relatively short ( $7-8$ text screens plus $2-3$ pictures; $400-550$ words). The texts dealt with physical geography, treating concepts like equator, earth rotation, rain, wind, atmospheric pressure, etc. Each student was allowed the time he/she needed to study the text screens and to perform the learning activities corresponding to the steps of the instructional strategy.

\section{Results}

To explore the intervention effects on the quality of the conceptions of the students during the training, a repeated measurement ANOVA with the two between-subjects factors Instruction and Familiarity and the within-subjects factor Training Time was carried out. Subjects assigned to the instructional 


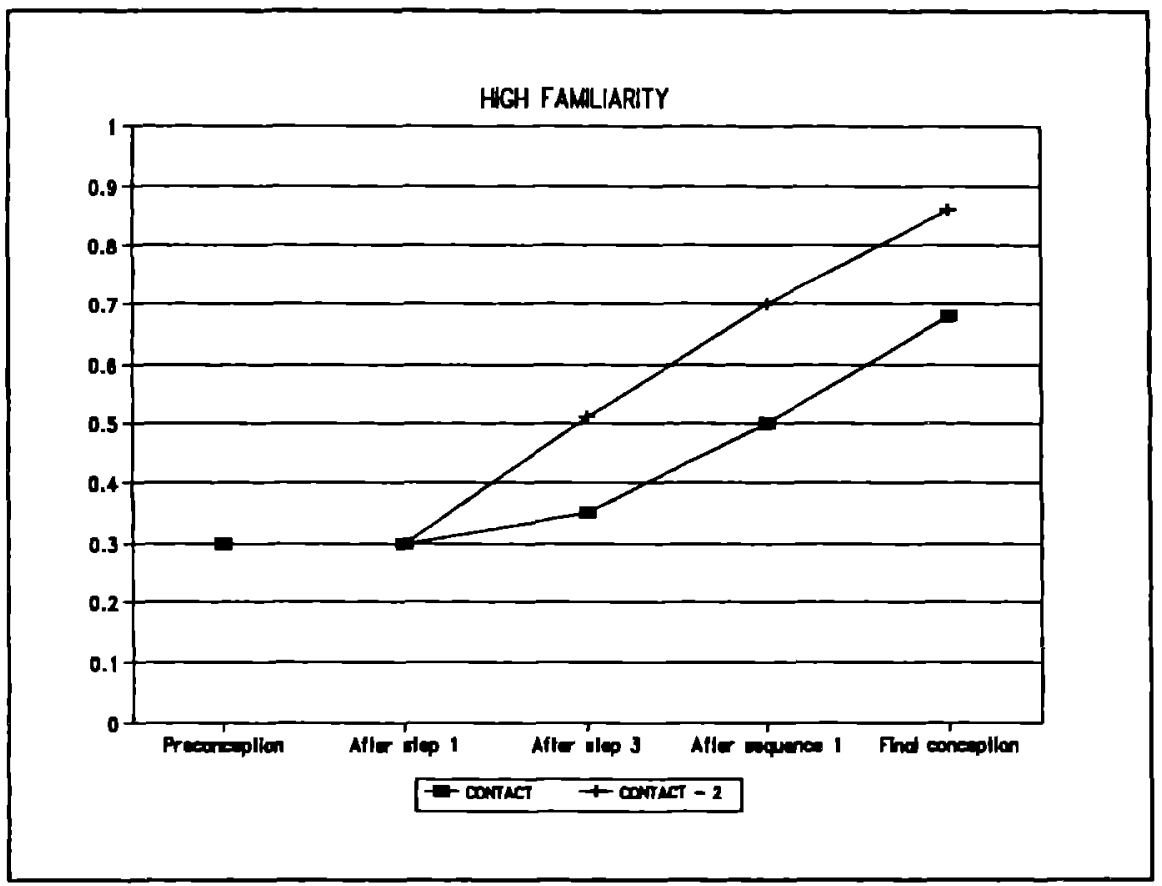

Figure $2 a$. Mean scores for the conditions CONTACT and CONTACT-2 with respect to the quality of the conceptions (as registered with various instructional steps during each training session) for the High familiarity group.

condition NO ACTIVATION were not included in this analysis because their conceptions had not been activated $(\mathrm{N}=50)$.

The main effects of the factors Instruction $(F(1,46)=2.44 ; p=0.12)$ and Familiarity $(F(1,46)=3.32 ; p=0.07)$ were not significant. The interaction effect between Instruction and Familiarity $(F(1,46)=0.77 ; \mathrm{p}=0.38)$ turned out not to be significant either. The analysis, however, revealed a significant interaction effect between Instruction, Familiarity and Training Time $(F(4,43)$ $=2.95 ; \mathrm{p} \leq 0.05$ ). For subjects who were very familiar with the concepts from the training texts, the CONTACT-2 strategy led to better conceptions than the CONTACT strategy from the third instructional step on ("formulating new conceptions") (see Figure 2a). For subjects who were not very familiar with these concepts, it was not until the second sequence of instructional steps, that the difference in quality of conceptions between the CONTACT- 2 condition and the CONTACT condition showed (see Figure $2 b$ ).

To examine whether the training had an effect on the quality of students' conceptions after the training and on their ability to apply these conceptions, a repeated measurement ANOVA with the two between-subjects factors 


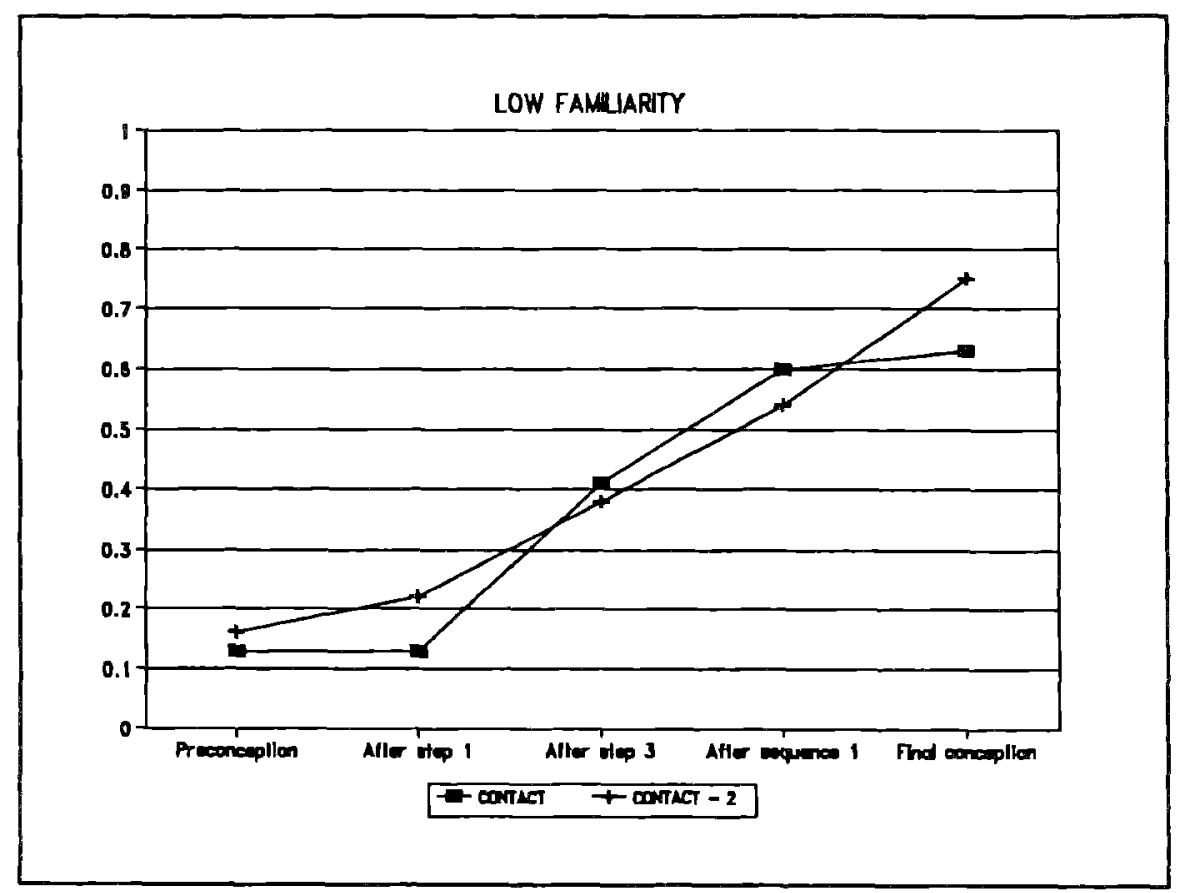

Figure $2 b$. Mean scores for the conditions CONTACT and CONTACT- 2 with respect to the quality of the conceptions (as registered with various instructional steps during each training session) for the Low familiarity group.

Instruction and Familiarity and the within-subjects factor Testing Time was carried out. Because of missing data of 5 subjects, this analysis was based on the data of 69 subjects.

A significant main effect of the factor Instruction $(\mathrm{F}(2,63)=6.65 ; \mathrm{p} \leq$ 0.005 ) was found. Subjects from the CONTACT-2 condition had higher scores on the idea and practice questions than subjects from the conditions CONTACT $(\mathrm{t}=3.38 ; \mathrm{p} \leq 0.001)$ and NO ACTIVATION $(\mathrm{t}=2.82 ; \mathrm{p} \leq 0.01)$. The difference between the conditions NO ACTIVATION and CONTACT $(\mathrm{t}=0.53 ; \mathrm{p}=0.60)$ was not significant (see Table 3 ). The main effect of the factor Familiarity $(F(1,63)=1.06 ; p=0.31)$ and the interaction effect between Instruction and Familiarity $(\mathrm{F}(2,63)=0.55 ; \mathrm{p}=0.58)$ were not significant. The interaction effects involving the within-subjects factor Testing Time turned out not to be significant as well.

To determine the training effects on students' learning performance on the posttest and the two retention tests, a repeated measurement ANOVA with two between-subjects factors (Instruction and Familiarity) and two withinsubjects factors (Relatedness and Testing Time) was performed. Because the 
Table 3. Mean scores, standard deviations and $\mathrm{N}$ of Ss per cell for the three instructional conditions on the idea and practice questions.

\begin{tabular}{llll}
\hline & M & Sd & N \\
\hline Contact & 0.45 & 0.15 & 23 \\
Contact-2 & 0.62 & 0.18 & 24 \\
No activation & 0.47 & 0.19 & 22 \\
\hline
\end{tabular}

Table 4. Mean scores, standard deviations and $\mathrm{N}$ of Ss per cell for the three instructional conditions on the learning performance tests.

\begin{tabular}{llll}
\hline & $\mathrm{M}$ & $\mathrm{Sd}$ & $\mathrm{N}$ \\
\hline Contact & 0.47 & 0.13 & 21 \\
Contact-2 & 0.62 & 0.14 & 22 \\
No activation & 0.51 & 0.15 & 22 \\
\hline
\end{tabular}

data of 9 subjects were missing, this analysis was based on the data of 65 subjects.

A significant main effect of the factor Instruction $(F(2,59)=6.16 ; \mathrm{p} \leq$ 0.005 ) was found. Subjects from the CONTACT- 2 condition had higher learning performance scores than subjects from the conditions CONTACT $(t=3.36$; $\mathrm{p} \leq 0.001)$ and NO ACTIVATION $(\mathrm{t}=2.53 ; \mathrm{p} \leq 0.01)$. No significant difference was found between the conditions NO ACTIVATION and CONTACT $(t=0.89$; $\mathrm{p}=0.37$ ) (see Table 4). The main effect of the factor Familiarity $(\mathrm{F}(1,59)=$ $0.01 ; \mathrm{p}=0.94)$ and the interaction effect between Instruction and Familiarity $(\mathrm{F}(2,59)=0.36 ; \mathrm{p}=0.70$ ) were not significant (see Table 5).

The interaction effect between Instruction and Relatedness $(\mathrm{F}(2,59)=0.94$; $\mathrm{p}=0.40$ ) also tumed out not to be significant (see Table 6).

Table 5. Mean scores, standard deviations and $\mathrm{N}$ of Ss per cell for the three instructional conditions on the leaming performance tests, both for the Low familiarity group and the High familiarity group.

\begin{tabular}{llllllll}
\hline & \multicolumn{3}{c}{ Low familiarity } & & \multicolumn{3}{c}{ High familiarity } \\
\cline { 2 - 3 } & M & Sd & N & & M & Sd & N \\
\hline Contact & 0.48 & 0.12 & 8 & & 0.46 & 0.14 & 13 \\
Contact-2 & 0.62 & 0.16 & 11 & & 0.61 & 0.13 & 11 \\
No activation & 0.49 & 0.13 & 11 & & 0.53 & 0.16 & 11 \\
\hline
\end{tabular}


Table 6. Mean scores, standard deviations and $\mathrm{N}$ of Ss per cell for the three instructional conditions on the learning performance tests, both on questions that were directly related to the particular idea question and on questions that were less directly related.

\begin{tabular}{lllllllll}
\hline & \multicolumn{3}{c}{ Directly related } & & \multicolumn{3}{c}{ Less directly related } \\
\cline { 2 - 3 } & $\mathrm{M}$ & $\mathrm{Sd}$ & $\mathrm{N}$ & & $\mathrm{M}$ & $\mathrm{Sd}$ & $\mathrm{N}$ \\
\hline Contact & 0.48 & 0.12 & 21 & & 0.46 & 0.14 & 21 \\
Contact-2 & 0.63 & 0.12 & 22 & & 0.60 & 0.17 & 22 \\
No activation & 0.54 & 0.15 & 22 & & 0.48 & 0.16 & 22 \\
\hline
\end{tabular}

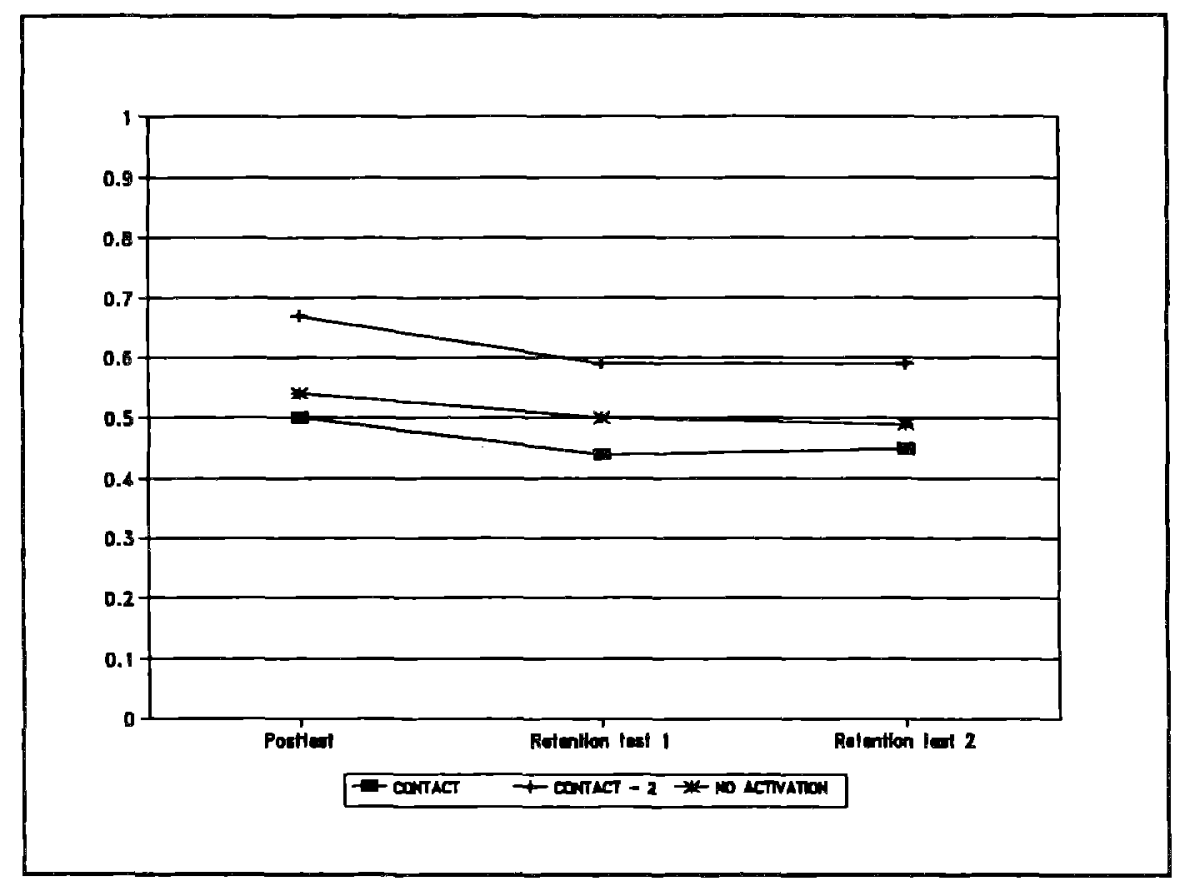

Figure 3. Mean scores for the three instructional conditions on the learning performance tests (posttest, first retention test and second retention test).

Moreover, the interaction effect between Instruction and Testing Time $(\mathrm{F}(4,114)=0.56 ; \mathrm{p}=0.69)$ was not significant (see Figure 3 ).

The SLS data were analysed by means of a repeated measurement ANOVA with two between-subjects factors (Instruction and Familiarity) and one within-subjects factor (SLS-scale). This analysis revealed a significant main effect of the factor Instruction $(\mathrm{F}(2,68)=7.44 ; \mathrm{p} \leq 0.001)$ : significant differences were found between the conditions CONTACT and NO ACTIVATION $(\mathrm{t}=$ $3.70 ; \mathrm{p} \leq 0.001)$ and CONTACT 2 and NO ACTIVATION $(\mathrm{t}=2.82 ; \mathrm{p} \leq 0.01)$. 
Table 7. Mean scores, standard deviations and $\mathrm{N}$ of Ss per cell for the three instructional conditions on the two parts of the SLS.

\begin{tabular}{lllllll}
\hline & \multicolumn{2}{c}{ Part I } & & \multicolumn{2}{c}{ Part II } & \\
\cline { 2 - 3 } & M & Sd & & M & Sd & N \\
\hline Contact & 0.63 & 0.16 & & 0.68 & 0.15 & 25 \\
Contact-2 & 0.59 & 0.11 & & 0.65 & 0.15 & 25 \\
No activation & 0.54 & 0.12 & & 0.54 & 0.16 & 24 \\
\hline
\end{tabular}

Subjects from the conditions CONTACT and CONTACT-2 had higher scores on the two parts of the SLS than subjects from the condition NO ACTIVATION. Between the conditions CONTACT and CONTACT $2(t=0.91 ; \mathrm{p}=0.36)$, no significant difference was found (see Table 7).

The main effect of the factor Familiarity $(\mathrm{F}(1,68)=5.66 ; \mathrm{p} \leq 0.05)$ was also significant: "highly familiar" subjects $(0.64)$ had higher scores on the two parts of the SLS than subjects who were not very familiar with the central concepts from the texts $(0.57)$. The interaction effect between Instruction and Familiarity $(\mathrm{F}(2,68)=0.07 ; \mathrm{p}=0.93)$ was not significant. Moreover, the interaction effects involving the within-subjects factor SLS-scale tumed out not to be significant.

\section{Conclusions and discussion}

The main conclusion drawn from our previous study (see for more details Biemans, 1994; Biemans and Simons, 1993; 1995) was that the original CONTACT strategy (see also Ali, 1990) is effective in the sense that students construct correct conceptions that represent the relations between the central concepts from the learning task (especially students who are already very familiar with these concepts), but ineffective in the sense that students mainly seem to concentrate on these central concepts and not on the whole text. Therefore, in the present study, the effectiveness of a revised variant of the CONTACT strategy, the so-called CONTACT-2 strategy, was examined. The CONTACT- 2 strategy is characterised both by adaptations to solve the problem of selective attention (see also Machiels-Bongaerts, 1993) and by adaptations to increase the efficiency and flexibility of the original CONTACT strategy. We hypothesized that these adaptations would result in increased effectiveness of the instructional strategy in terms of conceptions and learning performance, both for "highly familiar" students and for students who were not very familiar with the central concepts from the training texts. Moreover, we hypothesized that this increased effectiveness would not depend on the degree of concep- 
tual resemblance between the performance test questions and the "exposing events" (the idea questions) and on the moment of testing.

In general, the present study appears to confirm our hypotheses. The CONTACT-2 strategy appears to be more effective as a process-oriented instructional strategy aimed at supporting the process of conceptual change than the CONTACT strategy: the CONTACT- 2 strategy leads to better conceptions at the end of the training sessions. The stage in which the difference between the two strategies in quality of conceptions shows, depends on the degree of familiarity with the central concepts from the learning task (as in our previous study, a high degree of familiarity as reported by a student before formal instruction indicates that he/she has constructed more elaborated (mis)conceptions as a result of former learning experiences; see also Biemans, 1994; Biemans and Simons, 1993; 1995).

For students who are already very familiar with these concepts, the CONTACT-2 strategy leads to better conceptions than the CONTACT strategy from the third instructional step on. During this step, students formulate a new conception based on the previous step ("comparing and contrasting the preconception with the new information"). With respect to these two instructional steps, the CONTACT-2 strategy is characterised by various adaptations. During the step "comparing and contrasting the preconception with the new information", the crucial concepts are accentuated in different colours to focus the student's attention on the essential elements from his/her conception and from the text. During the step "formulating a new conception", the idea question is presented in both a textual and a visual mode to optimize the opportunity for the student to activate his/her conception ("multiple bridging"; see also Spiro, Feltovich, Jacobson and Coulson, 1991). During both steps, the student can ask for strategic information when he/she is executing a particular step. Moreover, monitoring questions are posed to check if the student understands what to do with that step. Apparently, these adaptations result in increased effectiveness of the strategy: the execution of the particular steps is supported in a more efficient way.

Students who are not very familiar with the central concepts from the texts do not seem to hold many (mis)conceptions before formal instruction because of a lack of former learning experiences (see also Ali, 1990). During the first sequence of instructional steps, these students seem to be mainly involved in knowledge construction processes aimed at constructing a conception. At this stage, both strategies lead to conceptions of comparable quality. During the second sequence of steps, however, these students have their conception from the first sequence as a starting point and they can get involved in conceptual change processes (aimed at relating their conception with the information from the leaming task and at correcting their conception if necessary). It is 
not until this stage that the benefits of the CONTACT- 2 strategy become clear: the difference in quality of conceptions between the CONTACT-2 strategy and the CONTACT strategy shows.

These assumptions seem to be confirmed by the SLS data: "highly familiar" students had higher scores on the two parts of the SLS than students who were not very familiar with the central concepts from the texts. They identified more activities aimed at conceptual change and they reported a higher frequency of using these activities: apparently, "highly familiar" students are more involved in conceptual change processes during learning while students who are not very familiar with the central concepts from the learning task are more concerned with knowledge construction processes (see also Biemans, 1994; Biemans and Simons, 1993; 1995).

The results showed that students who studied the training texts guided by the CONTACT-2 strategy had better conceptions after the training than students from the conditions CONTACT and NO ACTIVATION and were able to apply these conceptions in a more adequate way. These findings seem to confirm the conclusions drawn above: the CONTACT-2 strategy leads to conceptions of the highest quality that can be transferred to other problem-solving situations, even after a longer period (see Simons and Verschaffel, 1992). The original CONTACT strategy, on the other hand, does not lead to better conceptions (in the longer term) than the control condition NO ACTIVATION. Students assigned to the CONTACT condition and the CONTACT- 2 condition did not differ with respect to the number of correctly identified learning activities (that could be performed to construct a correct conception) and with respect to the frequency of using these activities. Apparently, these students perform comparable learning activities in similar frequencies (activated by the particular instructional strategy). However, students who are supported by the CONTACT-2 strategy seem to do this in a more efficient way: they construct more valid conceptions with more adequate retrieval paths (see also Schmidt, 1982).

Concerning students' learning performance as measured by the posttest and the two retention tests, a comparable training effect was found: students from the CONTACT-2 condition had higher leaming performance scores than students from the conditions CONTACT and NO ACTIVATION (no significant difference was found between the conditions NO ACTIVATION and CONTACT). Thus, the CONTACT-2 strategy did not only lead to conceptions of the highest quality but also to the best learning performance.

During the whole training, students from the CONTACT- 2 condition needed less time to finish a session than students from the CONTACT condition. Thus, the CONTACT- 2 strategy also proved to be more efficient than the original CONTACT strategy with respect to time costs. Students from the NO ACTIVATION condition, on the other hand, took less time than students from the CONTACT-2 
condition. However, both groups spent about the same amount of time studying the text itself. The total time difference could be explained by the time that CONTACT-2 students needed to do the learning activities corresponding to the steps of the instructional strategy. At the end of the training, this time difference had been halved without affecting differences in learning performance (see also Ali, 1990). Therefore, in our view, time on task phenomena could not be held responsible for the training effects mentioned above.

In our previous study, a negative side effect of the original CONTACT strategy was found: students who studied the training texts guided by the original CONTACT strategy seemed to focus more on the relations between the central concepts from the texts (as represented by idea questions and answer alternatives) and less on the other information to be leamed. Therefore, the CONTACT strategy was adapted in several respects to solve this problem of selective attention (see also Machiels-Bongaerts, 1993). These adaptations were aimed at spreading students' attention (in the sense that they are not just focused on giving a correct answer to the idea question but also on studying the text as a whole).

The present study showed that these adaptations did indeed result in the desired effect: the students who had been assigned to the CONTACT- 2 condition achieved the best learning performance scores, both on directly related questions and on less directly related questions. In our view, students who study texts guided by the CONTACT-2 strategy, have more information processing capacity left for studying the other information from the learning task because they perform the learning activities corresponding to the various instructional steps in a more effective and efficient way. They appear to use this attention and memory capacity to study the text as a whole in a more profound way. The CONTACT-2 strategy seems to support them in doing this because the goal of the training (comprehension of the whole text) is stressed, all important concepts from the learning material are accentuated and scrolling options are optimized. Students can also pay more attention to the text itself because the amount of strategic information they are obliged to read, is reduced, and because the second sequence of instructional steps is not presented if they have a correct conception at the end of the first sequence.

Based on the findings of this study, one could argue that the CONTACT2 strategy is more effective as instructional strategy aimed at conceptual change than the other two conditions because students construct conceptions that represent the relations between the central concepts from the learning task more accurately. Therefore, this study provides additional empirical support for the underlying activation model (see also Ali, 1990) that is based on the cognitive and instructional conditions formulated by Nussbaum and Novick (1982), Strike and Posner (1985), Prawat (1989) and others. Moreover, the 
effectiveness of the CONTACT-2 strategy appears not to be dependent on the degree of conceptual resemblance between the performance test questions and the "exposing events" (the idea questions) and on the moment of testing.

To summarize, the adaptations of the CONTACT strategy did indeed result in an increase in efficiency and flexibility of the strategy and in an adequate solution to the problem of selective attention: the students' attention is drawn to the learning task as a whole and not just to the relations between the central concepts. In our view, the results of this study support the following conclusion with respect to the design of process-oriented instructional strategies aimed at activation of prior knowledge: on the one hand, such instructional strategies should support all processes involved in conceptual change and, on the other hand, they should draw the student's attention to the learning task as a whole.

However, with this conclusion, other questions arise. Although our last study showed that it is possible to help fifth- and sixth-graders (primary education) to use their prior knowledge actively by means of a process-oriented instructional strategy presented through computer-assisted instruction, it is still unclear, however, what exactly causes the effectiveness of the strategy. A rather complex learning environment was designed that turned out to be effective in promoting conceptual change. But what are the essential ingredients? Can some steps and instructional measures be skipped? Can stripped versions of the strategy also be made effective? New dismantling studies seem necessary to answer these questions. Of course, other kinds of research are needed too. For instance, it seems important to study the generalizability of the instructional strategy to other domains and other subject groups.

In our next study, however, these lines of research will not be pursued. Instead, we will focus on another aspect of the CONTACT-2 strategy: the strategy is characterised by a rather high degree of extemal control. As was shown in the present study, a high degree of external control can result in conceptions of higher quality and in better learning performance, but it can also lead to greater dependence on external support (see also Biemans and Simons, 1992). In our view, this is an undesirable side effect in the longer term. Moreover, it would be impossible to design instructional programmes for all subject matter following the CONTACT-2 strategy. Therefore, it would be preferable to teach students how to use the steps of the strategy on their own or, in other words, to teach students how to activate their own preconceptions and how to construct correct conceptions. This seems to require quite another instructional approach: a "learning-to-learn" approach aimed at enhancing self-regulated learning (see also Jonassen, 1991). Therefore, in our next study, the CONTACT-2 strategy will serve as the starting point for such a "learning-to-learn" training procedure. The main goal of our next 
study will be to examine to what extent the learning activities corresponding to the various steps of the CONTACT- 2 strategy can be learned. Domain and target population will be the same as in the previous studies. The strategy will be implemented in a computer-assisted training program aimed at teaching students how to perform the various CONTACT-2 activities themselves. Therefore, external control will be gradually withdrawn ("scaffolding"; see also Reeve, Palincsar and Brown, 1987). With the first instructional condition, the amount of strategic support will be gradually withdrawn per step (see also Biemans and Simons, 1992) while, with the second condition, the number of instructional steps will be reduced as the training proceeds. The CONTACT2 condition from the second study will serve as control condition. Again, dependent variables will concern quality of conceptions and learning performance. In addition, students' ability to perform learning activities aimed at conceptual change will be measured. The results of this study should shed some light on the instructional conditions required to teach students how they themselves can initiate and perform learning activities aimed at conceptual change.

\section{References}

Ali, K. S. (1990). Instructiestrategieën voor het activeren van preconcepties [Instructional strategies to activate preconceptions]. Doctoral dissertation. Helmond: Wibro.

Biemans, H. J. A. (1989), Effecten van een metacognitief trainingsprogramma [Effects of a metacognitive training program]. Tijdschrift voor Onderwijs research, 14, 286-296.

Biemans, H. J. A. (1994). Activation of preconceptions as part of process-oriented instruction, in F. P. C. M. de Jong \& B. H. A. M. van Hout Wolters, eds., Process-oriented instruction. Ansterdam: VU University Press.

Biemans, H. J. A. \& Simons, P. R. J. (1992). Leaming to use a word processor with concurrent computer-assisted instruction. Learning and Instruction, 2, 321-338.

Biemans, H. J. A. \& Simons, P. R. J. (1993, August-September). The activation of preconceptions: the CONTACT strategy dismantled and adapted. Paper presented at the Fifth Conference of the European Association for Research on Learning and Instruction, Aixen-Provence, France.

Biemans, H. J. A. \& Simons, P. R. J. (1995). How to use preconceptions? The ConTACT strategy dismantled. European Journal of Psychology of Education, 10, 243-259.

Dochy, F. J. R. C. (1988). Het effect van de prior knowledge state op het leren: theorieën en onderzoek [The effect of the prior knowledge state on leaming: theories and research]. Heerlen: Open University.

Dochy, F. J. R. C. (1992). Assessment of prior knowledge as a determinant for future learning. Doctoral dissertation. Heerlen: Open University.

Eylon, B. \& Linn, M. C. (1988). Learning and instruction: an examination of four research perspectives in science education. Review of Educational Research, 58, 251-301.

Hegland, S. \& Andre, T. (1992). Helping leamers construct knowledge. Educational Psychology Review, 4, 223-240.

Hewson, P. W. \& Hewson, M. G. A. (1984). The role of conceptual conflict in conceptual change and the design of science instruction. Instructional Science, 13, 1-13. 
Jonassen, D. H. (1991). Objectivism versus constructivism: do we need a new philosophical paradigm? Educational Technology: Research and Development, 39, 5-14.

Machiels-Bongaerts, M. (1993). Mobilizing prior knowledge in text processing: the selectiveattention hypothesis versus the cognitive set-point hypothesis. Doctoral dissertation. Maastricht: University of Maastricht.

Nussbaum, J. \& Novick, S. (1982). Alternative frameworks, conceptual conflict and accommodation: towards a principled teaching strategy. Instructional Science, 11, 183-200.

Pfundt, H. \& Duit, R. (1991). Students' alternative frameworks and science education (3rd edition). Kiel: I.P.N.

Prawat, R. S. (1989). Promoting access to knowledge, strategy and disposition in students: a research synthesis. Review of Educational Research, 59, 1-41.

Reeve, R. A., Palincsar, A. S. \& Brown, A. L. (1987). Everyday and academic thinking: implications for learning and problem solving. Joumal of Curriculum Studies, 19, 123133.

Schmidt, H. G. (1982). Activatie van voorkennis, intrinsieke motivatie en de verwerking van tekst [Activation of prior knowledge, intrinsic motivation and text processing]. Apeldoorn: Van Walraven.

Simons, P. R. J. \& Verschaffel, L. (1992). Transfer. onderzoek en onderwijs [Transfer. research and education]. Tijdschrift voor Onderwijsresearch, 17, 3-16.

Spiro, R. J., Feltovich, P. J., Jacobson, M. J. \& Coulson, R. L. (1991). Cognitive flexibility, constructivism and hypertext: random access instruction for advanced knowledge acquisition in ill-structured domains. Educational Technology, 5, 24-33.

Strike, K. A. \& Posner, G. J. (1985). A conceptual change view of leaming and understanding, in L. H. T. West \& A. L. Pines, eds., Cognitive structure and conceptual change. Orlando: Academic Press.

Vermunt, J. D. H. M. (1992). Leerstijlen en sturen van leerprocessen in het hoger onderwijs: naar procesgerichte instructie in zelfstandig denken [Learning styles and regulation of learning in higher education: towards process-oriented instruction in autonomous thinking]. Doctoral dissertation. Lisse: Swets and Zeitlinger.

Voss, J. F. (1987). Learning and transfer in subject-matter learning: a problem-solving model. International Joumal of Educational Research, 11, 607-622. 